\title{
Vapor-phase molar Kerr constant values from solution
}

\section{measurements}

\author{
Victor Prezhdo $^{a}$, Karol Olan $^{\mathrm{a}^{*}}$, Oleg Prezhdo ${ }^{\mathrm{b}}$, Valentina Zubkova ${ }^{\mathrm{a}}$
}

${ }^{a}$ Institute of Chemistry, Jan Kochanowski University, 15 Swietokrzyska Str., 25-406 Kielce, Poland

${ }^{\mathrm{b}}$ Department of Chemistry and Physics, University of Rochester, Rochester, NY 14627, USA

\begin{abstract}
A method is proposed for determination of molar Kerr constants $(\mathrm{mK})$ by extrapolation of the values measured in a series of selected solvents. The $m K$ values of 19 organic compounds were calculated. Most of the compounds cannot be studied in the vapour phase. The discrete-continuum solvation model was applied to investigate the influence of solvent nature on solubility of the compounds under investigation. It is shown that universal interactions between the solvent and solute molecules, including the dispersive, inductive, and dipole-dipole interactions, dominate the solvation process. The optimum model of internal field was chosen to determine the Kerr constant. The values of $\boldsymbol{m} \boldsymbol{K}_{\text {gas }}$ measured experimentally coincide with the values of $m K_{\varphi_{\alpha}=0}^{\prime}$ that were obtained by extrapolation of $m K$ '. Hence, this method can be applied to calculate the values of molar Kerr constants on the basis of measurements in solutions.
\end{abstract}

KEYWORDS: molar Kerr constants, polarizability, vapor-phase, intermolecular interactions, London-Debye-Keesom potentials

\section{INTRODUCTION}

The most important characteristics of electrical properties of a molecule are its polarizability ( $\alpha$ and the dipole moment ( $\mu$ ) because they directly denote properties of the electron shell of the molecule. The dipole moment (DM) and polarizability determine the interaction forces, the forces that cause absorption, adhesion in case the distance between molecules decreases, transform gases into liquids, stabilize molecular crystals etc.

The detemination of DM and average polarizability of molecules (on the basis of molecular refraction) is quite simple nowadays. The molecular anisotropy and 
polarizability ellipsoids of molecules have been studied to less extent, especially their changes when molecules take part in various intermolecular interactions. It is caused by the fact that determination of such changes implies nontrivial electro-optical methods of investigation (the electro-optic Kerr effect) [1-3]. The double refraction in an electric field, the electro-optic Kerr effect, is connected to the polarizability anisotropy of molecules. If refractive index in the absence of an electric field is equal to $n$, it becomes equal to $n_{p}$ for a ray with oscillating electric vector parallel to the field $(E)$, and for perpendicular orientation $n_{s}$. If a ray of light is perpendicular to the field, it creates a path difference, $\Delta=n l\left(n_{p}-n_{s}\right) / \lambda$, where $l$ is the length of the ray of light in the field.

The electro- optic Kerr effect is expressed by the equation:

$$
D=2 \pi\left(n_{p}-n_{s}\right) / \lambda=2 \pi B l E^{2},
$$

where $D$ stands for birefringence, rad; $B$ is the specific value for each substance, and is called the Kerr constant.

The modern theory of the Kerr effect takes into account the contributions of various physical properties [4,5]. The theory is based on calculations of the interaction energy of a polar or anisotropically polarizable molecule with the electric field:

$$
U=-\sum_{i} \mu_{i} F_{i}-\sum_{i, j} a_{i j} F_{i} F_{j}
$$

where $\mu$ and $a_{i j}$ are the constituents of the DM vector and of the static polarizability tensor; $F_{i}$ are the constituents of the intensity vector of an electric field acting on the molecule.

G. Briegleb [6] introduced the molar Kerr constant $(m K)$ as the difference in molecular refractions for a ray of light with the orientation of an electric vector parallel $\left(M R_{p}\right)$ and perpendicular $\left(M R_{s}\right)$ to the field, which falls on the distance of $1 \mathrm{~cm}$ in a single electric field:

$$
M R_{p}-M R_{s}=\left[\frac{n_{p}^{2}-1}{n_{p}^{2}+2}-\frac{n_{s}^{2}-1}{n_{s}^{2}+2}\right] \frac{M}{d}=\frac{n_{p}-n_{s}}{n} \frac{6 n^{2}}{\left(n^{2}+2\right)^{2}} \frac{M}{d}
$$

where $M$ is the molar weight of a substance, and $d$-its density.

Taking into consideration the internal field 


$$
m K=\frac{M R_{p}-M R_{s}}{F^{2}}=\frac{n_{p}-n_{s}}{n} \frac{54 n^{2}}{\left(n^{2}+2\right)^{2}(\varepsilon+2)^{2}} .
$$

and applying Eq. (1), we obtain

$$
m K=\frac{6 B \lambda n}{\left(n^{2}+2\right)^{2}}\left(\frac{3}{\varepsilon+2}\right)^{2} \frac{M}{d} .
$$

Most data on the values of molar Kerr constant $(m K)$ available in the literature were obtained by measurements in diluted solutions of non-polar solvents; however, some research on $m K$ in crystals [7] has been carried out to show their better practical application [8-10]. The values of $m K$ determined on the basis of measurements in solutions depend on the nature of solvents [11-17], what can be explained by the interaction between the molecules of the solute and the solvent (solvent effect). Since the values of $m K$, which are based on the analysis of polarizability, in many cases appear most sensitive to the mutual orientation of bonds and the effects of electrons displacement, what makes them indispensable in the conformational analysis, it is very important to posess the experimental values of $m K$, obtained by measurements in the gas phase. There is very little published data on the measurements of $m K$ in the gas phase [14] because most organic compounds undergo decomposition before the transition into the gas phase [18]. That is why it is essential, taking into consideration the solvent effect, to propose a technique that makes it possible to obtain the values of the molar Kerr constant in the vapour phase on the basis of measurements in solvents.

A range of empirical equations was proposed to evaluate the solvent effect quantitatively, which link $m K$ with the macroscopic characteristics of the medium - the dielectric permittivity (g) and the refractive index $(n)$.

A critical analysis of these equations can be found in Ref. [11, 12]. None of these equations takes into account all factors that determine the non-specific influence of a solvent on the molecular characteristics. Moreover, these equations cannot be applied to the dependence of different types of intermolecular interactions on the properties of molecules of a solvent and of the structure of solutions [11]. 
For example, in Ref. [15] the dependence of $m K$ from $\frac{n^{2}-1}{n^{2}+2}$ was determined. The extrapolation of this dependence to $n=1$ fairly presents the values of $m K$ in the gas phase ( $\left.m K_{\text {gas }}\right)$; however, from the theoretical point of view such correlation is not totally correct because the parameter of $\frac{n^{2}-1}{n^{2}+2}$ (refraction) reflects the trace of polarizability tensor of a molecule, which does not depend on the deviator.

The dependence of $m K$ of anisotropic non-polar molecules dissolved in an isotropic solvent [16] was proposed on the basis of classical static-mechanical theories. A relative decrease of $m K$ in solution compared to $m K_{\text {gas }}$ is as following:

$$
\frac{m K-m K_{g a s}}{m K_{g a s}}=\frac{\alpha_{1}}{\alpha_{2 z z}-\alpha_{2 x x}}\left[2\left(2 \alpha_{2 z z}+\alpha_{2 x x}\right)\left\langle T_{z z}^{(1)}\right\rangle+3 v_{1}\left\langle T_{z z}\right\rangle\right]
$$

The proposed model contains one molecule of non-polar solute with polarizability $\alpha$ surrounded by $N_{\mathrm{A}}-1$, the molecules of an anisotropic solvent with polarizability $\alpha$. The anisotropy in distribution of solvent molecules around one molecule of a solute is described by the correlation tensor $\varangle_{\phi}>$. However, as the author states himself, the model is somehow simplified.

The influence of a solvent on the value of the Kerr constant $B$ was studied on the basis of ideas about the non-specific interactions of inductive and dispersive nature [19]. It was shown that, for blends of non-polar substances, the deviations from additivity of the Kerr constants $\not B$ are proportional to the excessive energies of dispersive interactions.

$$
\begin{gathered}
\Delta U_{12}=\left(U_{11} \cdot U_{22}\right)^{1 / 2}-0.5\left(U_{11}+U_{22}\right), \\
\Delta B_{12} \sim \Delta U_{12} f_{1} f_{2}=\left[\left(\frac{0.75 I_{1} b_{1}^{2}}{r_{11}^{6}} \frac{0.75 I_{2} b_{2}^{2}}{r_{22}^{6}}\right)-0.5\left(\frac{0.75 I_{1} b_{1}^{2}}{r_{11}^{6}}+\frac{0.75 I_{2} b_{2}^{2}}{r_{22}^{6}}\right)\right] f_{1}\left(1-f_{1}\right),
\end{gathered}
$$

where $r_{\mathrm{i}}$ is the distance between molecules calculated from the molecular volumes, $b_{\mathrm{i}}-$ main polarizability axes of molecules, $I_{\mathrm{i}}$ are the ionization potentials of molecules, $f_{i}$ - mole fractions of the components. If one of the components, for example 2 , is polar, we observe the contribution of induction and orientation interaction: 


$$
\begin{gathered}
\Delta B_{12} \sim\left[\frac{2 \mu_{2}^{2} b_{1}}{r_{12}^{6}}-0.5\left(\frac{2}{3 k T} \frac{\mu_{2}^{4}}{r_{22}^{6}}+0.75 \frac{I_{1} b_{1}^{2}}{r_{11}^{6}}\right)\right] f_{1}\left(1-f_{1}\right), \\
r_{12}=\left(r_{11}+r_{22}\right) / 2 .
\end{gathered}
$$

A very important role in determination of $m K$ plays the mutual orientation between the molecules of the solute and the solvent due to the dispersive, dipole-induced dipole, and dipole-dipole interactions. The influence of intermolecular field interaction on the value of dipole moments ( $\not$ ) of the molecules was calculated by the authors with the use of LondonDebye-Keesom potentials [20]. This allowed us to obtain the correlation between the values of $\mu$ and the characteristics of molecular structure of a liquid and, hence, to evaluate the participation of field interactions of different kinds in solutions.

It was of great interest to apply the approach mentioned above and evaluate the influence of universal interactions in solutions on the value of $m K$. Hence, the paper aims to establish a correlation between the molar Kerr constants and the parameters that determine universal and specific interactions of molecules in solvents. This gives grounds to determine the values of the molar Kerr constant in the vapour phase and study the space and electron structure of molecules.

\section{THEORETICAL METHODS}

\section{DISCRETE-CONTTINUUM MODEL}

In dilute solutions, only solvent molecules surround every solute molecule in the first coordination sphere. Therefore, the energy of interaction between the individual solute molecules is very small (Fig. 1).

The energy of universal interactions $[\mathbf{2 1 , 2 2}]$ of the two molecules $i$ and $j$ in a solution consists of the energies of dispersive interaction [23]

$$
E_{\text {disp }}=\frac{3 I_{i} I_{j}}{2(4 \pi \varepsilon)^{2}\left(I_{i}+I_{j}\right)} \frac{a_{i} a_{j}}{R^{6}}
$$

dipole-dipole interaction

$$
E_{d-d}=\frac{2}{3} \frac{\mu_{i}^{2} \mu_{j}^{2}}{(4 \pi \varepsilon)^{2} k T R^{6}}
$$


and dipole-induced dipole interaction

$$
E_{d-i d}=\frac{1}{(4 \pi \varepsilon)^{2} R^{6}}\left(\alpha_{i} \mu_{j}^{2}+\alpha_{j} \mu_{i}^{2}\right)
$$

Here, $I$ is the ionization potential, $\alpha$ is polarizability, $\mu$ is the molecular dipole moment, $\varepsilon$ is the dielectric permittivity of the solution, and $R$ is the distance between the interacting molecules.

Thus, the energy of interaction of a solute molecule with solvent molecules may be expressed by Eq. (7)

$$
\Delta E=\frac{1}{(4 \pi \varepsilon)^{2}}\left(\frac{Z}{R^{6}}\right)_{1}\left[C_{d i s p} \frac{3}{2} \frac{I_{i} I_{j}}{I_{i}+I_{j}} \alpha_{i} \alpha_{j}+C_{d-d} \frac{2}{3} \frac{\mu_{i}^{2} \mu_{j}^{2}}{k T}+C_{d-i d}\left(\mu_{i}^{2} \alpha_{j}+\mu_{j}^{2} \alpha_{i}\right)\right] \text { (7) }
$$

The number of solvent molecules surrounding a solute molecule in the first coordination sphere $(Z)$ is expressed as $Z=\frac{1}{V_{j}}\left[\frac{4}{3} \pi R^{3}-V_{i}\right]$, where $\frac{4}{3} \pi R^{3}$ is the volume of the first coordination sphere, $V_{\mathrm{i}}$ is the volume of one solute molecule, $V_{1}$ is the volume of one solvent molecule, and $R$ is the radius of the first coordination sphere. The latter may be expressed as a sum of the radii of the solvent and solute molecules, $R=R_{\mathrm{i}}+R_{\mathrm{j}}$. The volumes of the solvent and solute molecules can be obtained by dividing molar volumes $V_{\mathrm{m}}$ by the Avogadro number $N_{\mathrm{A}}$. For instance, for the solute $V_{\mathrm{i}}=V_{\mathrm{mi}} / N_{\mathrm{A}}$.

The coefficients $C_{i}$ in the above equation are corrections for non-additivity of pairwise interactions. When investigating the same solute in a series of similar solvents, the corrections can be assumed constant [20], leading to

$$
\Delta E=\frac{1}{(4 \pi \varepsilon)^{2}}\left(\frac{Z}{R^{6}}\right)_{1} \overline{c o n s t}\left[\frac{3}{2} \frac{I_{i} I_{j}}{I_{i}+I_{j}} \alpha_{i} \alpha_{j}+\frac{2}{3} \frac{\mu_{i}^{2} \mu_{j}^{2}}{k T}+\left(\mu_{i}^{2} \alpha_{j}+\mu_{j}^{2} \alpha_{i}\right)\right] .
$$

Then, a change in property $|\Delta y|$ of the molecules in solution compared to the gas phase is proportional to the energy of the intermolecular interaction:

$$
|\Delta y|=y_{\text {gas }}-y_{\text {sol }} \sim \frac{1}{(4 \pi \varepsilon)^{2}}\left(\frac{Z}{R^{6}}\right)_{1}\left[\frac{3}{2} \frac{I_{i} I_{j}}{I_{i}+I_{j}} \alpha_{i} \alpha_{j}+\frac{2}{3} \frac{\mu_{i}^{2} \mu_{j}^{2}}{k T}+\left(\mu_{i}^{2} \alpha_{j}+\mu_{j}^{2} \alpha_{i}\right)\right] .
$$


In a series of non-polar solvents $(\not=0)$ for the same solute $\left(I_{i}=\right.$ const, $\mu_{i}=$ const, $\alpha=$ const), the energy of interaction can be expressed as

$$
|\Delta y| \sim \frac{1}{(4 \pi \varepsilon)^{2}}\left(\frac{Z}{R^{6}}\right)_{1}\left[\frac{3}{2} \frac{I_{i} I_{j}}{I_{i}+I_{j}} \alpha_{i} \alpha_{j}+\mu_{i}^{2} \alpha_{j}\right] \equiv \varphi
$$

In a series of non-polar solutes $(\mu=0)$ for the same polar solvent $\left(I_{j}=\right.$ const, $\mu=$ const, $\mathcal{Q}=$ const), Eq. (9) can be expressed as

$$
|\Delta y| \sim \frac{1}{(4 \pi \varepsilon)^{2}}\left(\frac{Z}{R^{6}}\right)_{1}\left[\frac{3}{2} \frac{I_{i} I_{j}}{I_{i}+I_{j}} \alpha_{i} \alpha_{j}+\mu_{j}^{2} \alpha_{i}\right] \equiv \varphi_{\alpha}^{*} .
$$

The connection between the interaction energy of molecules and the changes in properties of a substance is so evident that it is considered a non-alternative hypothesis. It is discussed from historical viewpoint, for example, in a recent book [24]. The dependences (9) - (11) were proved on the spectral characteristics of molecules such as IR-spectra $(\Delta)$, NMRspectra (proton chemical shift, $\left.\mathbb{1}_{\mathrm{I}}\right)$, and electronic absorption spectra $\left(E_{\max }, f\right)$ [25].

In the theory of dispersive interaction an equation (4) was obtained, which connects $E_{\text {disp }}$ with polarizability and the ionization potential of molecules. It was shown that for blends of non-polar compounds the deviations from additivity of the Kerr constants $\Delta \mathbf{B}$ proportionate to the excessive energies of dispersive interaction [19], and for polar compounds - to the energies of dipole-dipole interaction [26]. Since the Kerr constant (B) and the molar Kerr constant $(\mathrm{mK})$ are connected to the relation used most often [11]:

$$
m K=\frac{6 B \lambda n}{\left(n^{2}+2\right)^{2}(\varepsilon+2)^{2}} \frac{M}{d}
$$

where $n$ is the index of refraction, $\lambda$ is the wavelength, $\mathcal{E}$ - the dielectric permeability, $M$ is molar mass, $d$ - density, and $B$ - the Kerr constant, we can expect that $\Delta B=B_{\text {gas }}-B_{\text {sol }}, \Delta n K \sim$ $E$ (the interaction energy between solute and solvent molecules).

To check the trend expressed by Eq. (10), we examined the reference data [14] on $m K$ in a series of non-polar solvents with similar values of the ionization potential $\left(I_{j}\right)$. The solvents included heptane, hexane, cyclohexane, tetrachloromethane, dioxane, benzene, and carbon bisulfide (Table 1). It is evident from Figs. 2 and 3 that the value of $|\Delta m K|$ increases in a series of solvents with similar values of $I_{j}$ according to Eq. (7) but the value of $m K$ 
decreases linearly with the increase in $\varphi_{\alpha}$ value. Further, larger values of $m K_{\text {gas }}$ lead to a greater slope of the line. In a series of non-polar substances with close $I_{i}$ in the same polar solvent

$\mathrm{C}_{6} \mathrm{H}_{5} \mathrm{Cl}$, the value of $|\Delta m K|$ linearly increases with rise in the parameter of $\varphi_{\alpha}^{*}$ (Table 2).

The influence of non-polar solvents on the value of $m K$ can be explained by the fact that as a result of solvation there are shells of solvent molecules being formed around the molecules of the solute; these shells of solvent molecules (Fig. 1), which are poorly oriented due to the dispersive and dipole-induced dipole interactions. These interactions contribute to inhibition of free rotation of the solute molecules and, according to the Langevin-Born orientation theory $[\mathbf{2 7}, \mathbf{2 8}]$, impede the orientation of molecules within the field and, consequently, lead to decrease in the value of $m K$. The dependence of $m K$ on the parameter of $\varphi$ which follows from Eq. (10), points at the volume nature of the field interaction of molecules in the solutions [29].

Local complexes are formed in case of a solvent that shows evident anisotropy of polarizability and ability to form the CT complexes such as benzene. The Kerr constant helps to determine the structure of such complexes according to the techniques proposed in Ref. $[30]$.

The values of $m K$ for nitrobenzene, 1,2-dinitrobenzene, and 1,3-dinitrobenzene (Fig. 2), and acetonitrile (Fig. 3) measured in benzene fall out from the general dependence and prove that these compounds with benzene form the complexes of $\pi \pi^{*}$ type. The substances, which are donors of protons, for example, chloroform, together with dioxane form the complexes with H-bond, what also leads to falling out of the value of $m K$ from the general dependence. In these cases, not single molecules but the whole complexes are oriented to the external field.

MODELS OF INTERNAL FIELD IN ORDER TO DETERMINE THE MOLAR KERR CONSTANT

There are many different equations in the literature on the subject for calculation of the molar Kerr constants in liquids, which give different values of $m K$. This is connected with modification of the orientation theory of the Kerr effect for condensed media. The theory was improved by the following: 1) modification of an internal field that has an effect on the molecule; 2) taking into account the effect of orientation correlations of molecules on the 
measured parameters; 3) determination of influence of the effects of an electric field on birefrigence, which were not taken into account by the Langevin-Born theory.

The internal field was modified in the two ways - 1) by the variation in contribution of the internal field to the expression of $m K$ retaining the Lorentz function, 2) by the substitution of this function for a more complex model. Thus, the Onsager theory [31] leads to the expression:

$$
m K=\frac{1}{(1-a f)(1-b g)}\left(m K^{0}-\frac{2 \pi N}{9} a f \Theta_{1}\right)
$$

where $f=2(\varepsilon-1) / r^{3}(2 \varepsilon+1) ; g=2\left(n^{2}-1\right) / r^{3}\left(2 n^{2}+1\right) ; r$ is an average radius of a molecule; $m K^{0}$ - a "true" molar Kerr constant; $a$ and $b$ are constants.

More general theories take into account the non-sphericity of molecules. According to the Scholte's theory [11]

$$
m K=\frac{2 \pi N}{9}\left[\begin{array}{l}
\frac{1}{45 k T} \frac{1}{(1-a f)(1-b g)} \sum\left(b_{i i} m_{i i}-b_{j j} m_{j j}\right)\left(a_{i i} k_{i i}^{2}-a_{j j} k_{j j}^{2}\right)+\frac{1}{45 k^{2} T^{2}} \frac{1}{(1-a f)(1-b g)} \times \\
\times \sum\left(b_{i i} m_{i i}-b_{j j} m_{j j}\right)\left(\mu_{i}^{2} k_{i i}^{2}-\mu_{j}^{2} k_{j j}^{2}\right)
\end{array}\right] .
$$

Here, $m_{i i}=\left(2 n^{2}+1\right) /\left[3 n^{2}+3\left(1-n^{2}\right) O_{i}\right] ; \quad k_{i i}=(2 \varepsilon+1) /\left[3 \varepsilon+3(1-\varepsilon) O_{i}\right] ; \quad O_{i}$ is the ellipticity factor [32].

The equations of this type have some parameters that are difficult to determine. The theories, in which the type of function of Lorentz internal field varies as $\left(n^{2}+2\right) / 3$ or $(\varepsilon+2) / 3$, were not related.

The eq. (15) - (17) are widely used. In Ref. [32] the molar Kerr constant was introduced, which takes into account the internal field according to Lorenz:

$$
m K=\frac{6 \lambda n B}{\left(n^{2}+2\right)} \cdot\left(\frac{3}{\varepsilon+2}\right)^{2} \cdot \frac{M}{d} .
$$

The phenomenological theory of the Kerr effect leads to the expression for $m K[\mathbf{3 3}]$ :

$$
m K^{\prime}=\frac{6 \lambda n B^{\prime} M}{3\left(n^{2}+2\right)^{2}(\varepsilon+2) d} .
$$


In Ref. [34] the equation was obtained on the basis of analysis of the relationship between the refraction and polarizability in anisotropic media:

$$
m K^{\prime \prime}=\frac{2 \lambda n B^{\prime \prime} M}{3\left(n^{2}+2\right)(\varepsilon+2) d} .
$$

Here $n$ stands for the refractive index, $\lambda$ is the wave length, $\varepsilon$ - dielectric permeability, $M$ is the molar mass, $d$ - density, $B$ - the Kerr constant. The classical approach to the Kerr theory implies

$$
B=\frac{3 \pi N_{1}}{n \lambda}\left(\frac{n^{2}+2}{3}\right)^{2}\left(\frac{\varepsilon+2}{3}\right)^{2}\left(\theta_{1}+\theta_{2}\right),
$$

where $N_{1}$ is the number of molecules in a unit of volume, $\theta$ - the anisotropic constituent of the Kerr constant, $\theta$ - the dipole constituent of the Kerr constant:

$$
B^{\prime}=\frac{3 B}{\varepsilon+2} ; \quad B^{\prime \prime}=B /\left(\frac{\varepsilon+2}{3}\right)\left(\frac{n^{2}+2}{3}\right)
$$

\section{RESULTS AND DISCUSSION}

It is easy to show [14] that $m K$ (the experimental molar Kerr constant) obtained on the basis of the diluted solutions in non-polar isotropic solvents according to Eq. (15) and $m K$ determined according to Eq.(16) correlate:

$$
m K^{\prime}=\frac{m K}{3\left(\varepsilon_{1}+2\right)},
$$

$m K$ and $m K$ " determined on the basis of Eq. (14) are brought into correlation:

$$
m K^{\prime \prime}=m K\left(\frac{\varepsilon_{1}+2}{3}\right)\left(\frac{n_{1}^{2}+2}{3}\right)
$$

Here $\&$ and $n_{1}$ stand for the dielectric permeability and refractive index correspondingly. The key choice criterion for the equation to calculate $m K$ was the coincidence of the values of $m K, m K^{\prime}$ and $m K^{\prime \prime}$ with the gas values of $m K_{\text {gas }}$ presented in Ref. [11]. However, as it was shown in several papers [12, 35-38], the value of $m K$ depends on the nature of a solvent. The authors have presented above that the influence of intermolecular field interaction on $m K$ can be determined by the London-Debye-Keesom potentials for pairwise interactions in condensed media. It was also shown that $\Delta n K=m K_{\text {gas }}-m K \sim \varphi$ for 
one and the same substance in a series of non-polar solvents with close first potentials of ionization and polarizability of molecules.

The authors of this paper suggest that the reproducibility of the value of $m K_{\text {gas }}$ using extrapolation of $m K$ as the function from $\varphi$ to $\varphi=0$ should be considered as the choice criterion for the equation to determine $m K$. Table 3 shows the values of $m K$ obtained according to the classical formula (12) in a series of non-polar solvents and the experimental

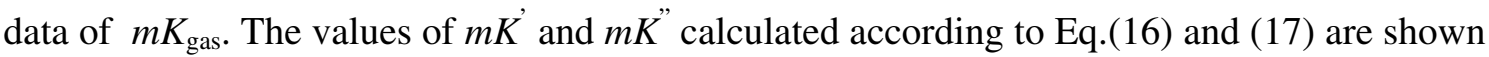
in Tables 4 and 5. The dependences of $m K$ on $\varphi_{w} w e r e$ suggested along with the extrapolation of $m K$ to $\varphi=0$ on the basis of the data in Tables 3-5. It is evident from the examples in Figs. 4-6 that in all cases, except $\mathrm{CCl}_{4}$, the extrapolation of $m K^{\prime}$ leads to $m K_{\text {gas }}$ measured experimentally. The above deviation is obviously connected with the deviation of $m K$ can be attributed to a greater error in determination of $m K_{\text {gas }} \mathrm{CCl}_{4}$ due to the small absolute value of $m K_{\text {gas }}\left(m K_{\text {gas }}\left(\mathrm{CCl}_{4}\right)=0.933\right)$. The extrapolation of the values of $m K$ and $m K^{\prime \prime}$ does not give the values of $m K_{\text {gas }}$.

In case of the solvents with evident anisotropy of polarizability and the ability to form CT complexes or H-bond, the values of $m K$ fall out sharply from the linear dependence, which describes the volume non-specific interaction of molecules in solvents; this points at the local interaction with formation of the complexes oriented in the electric field as a whole. This takes place, for example, in case of carbon disulphide in dioxane (Fig. 5), chloroform in dioxane, nitrobenzene in benzene etc.

\section{CONCLUSIONS}

The evaluation of the effect of the solute-solvent interaction on $m K$ of dissolved molecules using the London-Debye-Keesom potential allowed us to establish the correlations of $m K$ measured in a series of non-polar solvents, similar ionization potentials, and molecular size with the interaction parameter $\varphi_{k}$ The established dependence is relevant to the compounds which do not form $\mathrm{H}$-bonds and other specific interactions because the parameter $\varphi_{x}$ relates to the universal intermolecular interactions only.

Good coincidence between the values of $m K_{\text {gas }}$ measured experimentally and the values of $m K_{\varphi_{\alpha}=0}^{\prime}$ obtained by the extrapolation of $m K^{\prime}$, which were determined according to the formula (16) gives us a good reason to believe that it should be preferably used to calculate the values of molar Kerr constants on the basis of solutions. Moreover, the values of 
$m K_{\varphi_{\alpha}=0}^{\prime}$, the changes of which have not been made or just are impossible in the gaseous state (Table 4), were obtained by the extrapolation of the values of $m K$ to the zero value of $\varphi$ Thus, the method proposed by the authors can be applied to determine the gas values of molar Kerr constants on the basis of changes in a series of non-polar solvents with volume nature of interaction between the molecules of a solute and a solvent.

Determination of the values of molar Kerr constant in the vapour phase on the basis of solution measurements as it was presented allows us to apply the molar Kerr constants in various fields of chemistry. Especially it is important during the study of intramolecular effects, for which the theory of changes in internal field only was developed along with empirical studies on the polarizability anisotropy and conjugation. The qualitative studies on the polarizability as one of the main factors that determine the chemical behavior of molecules give grounds for modern electron theory [39].

\section{ACKNOWLEDGEMENTS}

OVP acknowledges financial support of the USA Department of Energy, grant No. DESC0006527.

\section{AUTHOR INFORMATION}

Corresponding Author

*E-mail: karolo12@vp.pl

\section{REFERENCES}

[1] O. Prezhdo, K. Olan, W. Zubkowa, W. Preżdo, Elektrooptyczny efekt Kerra w chemii (Electrooptical Kerr effect in chemistry), Wiadomości Chemiczne 65 (2011), 1-31 (in Polish).

[2] D.C. Clary, B.J. Orr (Eds.), Optical, Electric and Magnetic Properties of Molecules: A Review of the Work of A.D. Buckingham, first ed., Elsevier Science, Amsterdam, 1997.

[3] C.J.F. Bottcher, Theory of Electric Polarization, Vol.1: Dielectrics in Static Fields, second ed., Elsevier Science, Amsterdam, 1973.

[4] M.W. Wolkenstein, Structure and physical properties of molecule, first ed., TeubnerVerlagsgesellschaft, Leipzig, 1960 (in German).

[5] C.G. Le Fevre, R.J.W. Le Fevre, The Kerr effect. Its measurement and application in chemistry, Rev. Pure Appl. Chem. 5 (1955), 261-318. 
[6] G. Briegleb, Electro-optical Kerr constants of liquid and dissolved substances and the kinds of and reasons for the mutual influences and orientations of molecules in liquids. I, Z. Phys. Chem. 14B (1931), 97-104 (in German).

[7] M. Melnichuk, L.T. Wood, Direct Kerr Electro-optic Effect in Noncentrosymmetric Materials, Phys. Rev. 82A (2010), 013821-013829.

[8] R.L. Sutherland, Handbook of Nonlinear Optics, second ed, Marcel Dekker, New York, 2003.

[9] R.E. Newnham, Properties of Materials: Anisotropy, Symmetry, Structure, first ed., Oxford University Press, New York, 2005.

[10] M.V. Khashchina, S.A. Tyurin, V.V. Prezhdo, Electrooptical methods in engineering, first ed., Osnova, Kharkov (Ukraine), 1989 (in Russian).

[11] A.N. Vereshchagin, Polarizability of Molecules, first ed. Nauka, Moscow, 1980 (in Russian).

[12] G. Maroulis, T. Bancewicz, B. Champagne, A.D. Buckingham, Atomic and Molecular Nonlinear Optics: Theory, Experiment and Computation, first ed., IOS Press, AmsterdamBerlin-Tokyo-Washington, 2011.

[13] V.V. Prezhdo, G.V.Tarasova, O.V. Prezhdo, S.A. Tyurin, O.N. Akulova, T.N. Kurskaya, Electric Polarization of Onsager Fluids. II. Birefringence. 1. Kerr Constants of Pure Substances, Acta. Phys. Polonica 85A (1994), 797-802.

[14] A.N. Vereshchagin, Characteristics of Molecular Polarizability Anisotropy: Handbook, first ed., Nauka, Moscow, 1982 (in Russian).

[15] R.S. Armstrong, M.J. Aroney, C.G. Le Fevre, R.J.W. Le Fevre, M.R. Smith, Molecular polarizability. Dependence of apparent molar Kerr constants at infinite dilution on the medium in which they are measured, J. Chem. Soc. 4 (1958), 1474-1480.

[16] S.S. Batsanov, Dielectric methods of investigation on chemical bonds and the concept of electronegativity, Russ. Chem. Rev. 51 (1982), 1201-1224 (in Russian).

[17] V.E. Kataev, S.G Vul'fson, A.N. Vereshchagin, Analysis of the anisotropy polarizabilities in the gas, liquids, and solutions 2. The Kerr effect, Bulletin of Academy of Sciences of the USSR, Division of Chemical Science 29 (1980), 1760-1765

[18] B.E. Poling, J.M. Prausnitz, J.P. O'Connell, The Properties of Gases and Liquids, fifth ed.; McGraw-Hills Companies, New York, 2001.

[19] A.E. Lutskii, V.D. Berestetskaya, V.T. Chalyi, L.B. Vasilenko, Intermolecular intermolecular interactions and Kerr constant of binary mixtures, Russ. J. Gen. Chem. 43 (1973), 2462 - 2465 (in Russian). 
[20] O. Prezhdo, V. Zubkova, K.Olan, V. Prezhdo, A simple model for prediction of dipole moments of isolated molecules, J. Mol. Str. 1053 (2013), 141-149

[21] V.Yu. Senichev, V.V. Tereshatov, General principles Govering Dissolution of Materials in Solvents, in: G. Wypych (Ed.), Handbook of Solvents, William Andrew Publ., Toronto New York, 2001, 101-132.

[22] A.J. Misquitta, Intermolecular Interactions, in: J. Leszczyński (Ed.), Handbook of Computational Chemistry, Springer, Berlin, 2012, 360-430.

[23] I.G. Kaplan, Intermolecular Interactions: Physical Picture, Computational Methods and Model Potentials, first ed., Wiley, Weinheim (Germany), 2006.

[24] J. H. Bae, Intermolecular interaction for polar and nonpolar molecules correlated with properties of gases, Ulan Press, Burton, 2012.

[25] A.E. Lutskii, V.V. Prezhdo, L.I. Degtiareva, V.A. Gordienko, Spectroscopy of Intermolecular Field Interactions in Solutions Russ. Chem. Rev. 51 (1982), 1398-1423 (in Russian).

[26] A.E. Lutskii, V.D. Berestetskaya, M.V. Khashchina, V.T. Chalyi, Dipole-dipole interactions and Kerr constants of liquid binary mixtures, Russ. J. Gen. Chem. 43 (1973), 2597 - 2600 (in Russian).

[27] M. Jaszuński, A. Rizzo, A.K. Ruud, In: J. Leszczyński (Ed.), Handbook of Computational Chemistry, Springer: Berlin, 2012, 726-767.

[28] D.W. Davies, The theory of the electric and magnetic properties of molecules, John Wiley and Sons, London-N.Y.-Sydney, 1967.

[29] V.V. Prezhdo, G.V. Tarasova, O.V. Prezhdo, S.A. Tyurin, N.I. Ivanov, T.N. Kurskaya, Electric Polarization of Onsager Fluids. II. Birefringence. 3. Role of Universal Pairwise Interactions, Acta Phys. Polonica A89 (1996), 47-59.

[30] M.J. Aroney, The Electro-Optical Kerr Effect in Conformational Analysis. New analytical methods, Angewandte Chemie 16 (1977), 663-673.

[31] L. Onsager, Electric Moments of Molecules in Liquids, J. Am. Chem. Soc. 58 (1936), 1486-1493.

[32] C.J.F. Bottcher, P. Bordewijk, Theory of Electric Polarization, Vol. 2: Dielectrics in TimeDependent Fields, second ed., Elsevier Science, Amsterdam, 1980.

[33] V.A. Zamkov, Fenomenological theory of electrooptical Kerr effect, Optika i Spektroskopia 15 (1963), 654-658. 
[34] M.F. Vuks, The Magnitude of the Optical Anisotropy of the Benzene and Carbon Disulfide Molecules as Determined by Light Scattering in Solutions, PN, New York, 1953.

[35] V.V. Prezhdo, G.V. Tarasova, O.V. Prezhdo, S.A. Tyurin, O.N. Akulova, T.N. Kurskaya, Electric Polarization of Onsager Fluids. II. Birefringence. 2. Molar Kerr Constants of Binary Solutions, Acta Phys. Polonica A86 (1994), 327-332.

[36] K. Rajagopal, T.A.P. Rao, Temperature Dependence of Kerr Coefficient of Binary Liquid Mixtures of Aprotic-Aprotic Molecules, Phys. Chem. Liq. 38 (2000), 35-47.

[37] J.M. Neto, A.B. Villaverde, The electro-optical Kerr effect in binary mixtures of polar liquids, J. Phys. Condens. Matter 8 (1996), 2791-2800.

[38] J. Philip, T.A.P. Rao, Kerr effect in binary liquid mixtures, J. Mol. Liq. 50 (1991), 207214.

[39] W.B. Smith, Introduction to Theoretical Organic Chemistry and Molecular Modeling, first ed., Wiley-VCH, Oxford, 1996. 


\section{Figure captions}

Figure 1. Discrete-continuum model of interaction of a solute molecule (i) with solvent molecules $(\mathrm{j})$ in a medium with dielectric permittivity $\varepsilon$.

Figure 2. Dependence $m K$ - $\varphi_{k}$ for methanedithione (the — line), benzene (the --- line), and $\Delta n K-\varphi_{k}$ for methanedithione (the ..... line), benzene (the . . . line) in non-polar solvents, namely heptane $(\bullet)$, hexane $(\bullet)$, cyclohexane $(\square)$, tetrachloromethane $(\square)$, dioxane $(\Delta)$, benzene $(\boldsymbol{\Lambda})$, carbon bisulfide $(0)$.

Figure 3. Dependence $m K$ - $\varphi_{k}$ for nitrobenzene (the — line), 1,2-dinitrobenzene (the ..... line), 1,3-dinitrobenzene (the . . line), and $\Delta n K$ - $\varphi_{\mathrm{f}}$ or nitrobenzene (the --- line) in nonpolar solvents, namely heptane $(\bullet)$, hexane $(\bullet)$, cyclohexane $(\square)$, tetrachloromethane ), dioxane $(\Delta)$, benzene $(\boldsymbol{\Delta})$.

Figure 4. Dependence $m K$ - $\varphi$ for benzene: $m K$ (the — line), $m K^{\prime}$ (the --- line), and $m K^{\prime \prime}$ (the ... line) in non-polar solvents, namely heptane ( $\bullet)$, hexane $(\bullet)$, cyclohexane $(\square)$, tetrachloromethane $(\square)$, dioxane $(\Delta)$, benzene $(\Delta)$, carbon bisulfide $(0)$.

Figure 5. Dependence $m K$ - $\varphi_{\alpha}$ for methanedithione: $m K$ (the — line), $m K^{\prime}$ (the --- line), and $m K^{\prime \prime}$ (the _. line), and tetrachloromethane: $m K$ (the _ line), $m K^{\prime}$ (the _.. line), and $m K^{\prime \prime}$ (the .... line) in non-polar solvents, namely heptane $(\bullet)$,hexane $(\bullet)$, cyclohexane $(\square)$, tetrachloromethane $(\boldsymbol{\square})$, dioxane $(\Delta)$, benzene $(\Delta)$, carbon bisulfide $(0)$. For methanedithione the $m K$ scale is given in brackets.

Figure 6. Dependence $m K$ - $\varphi_{k}$ for acetonitrile: $m K$ (the — line), $m K^{\prime}$ (the --- line); for propanone: $m K$ (the ..... line), $m K^{\prime}$ (the . . . line); and $m K^{\prime \prime}$ (the _. line) in non-polar solvents, namely heptane $(\bullet)$,hexane $(\bullet)$, cyclohexane $(\square)$, tetrachloromethane $(\boldsymbol{\square})$, benzene $(\boldsymbol{\Delta})$. For propanone the $m K$ scale is given in brackets. 
Table 1. The values of molar Kerr constants $\left(m K \times 10^{12}\right)$ and $\varphi$ parameter $\left(\varphi \times 10^{18}\right)$ in non-polar solvents

\begin{tabular}{|c|c|c|c|c|c|c|c|c|c|c|c|c|c|c|c|}
\hline $\begin{array}{l}\text { Compou } \\
\text { nd }\end{array}$ & $\begin{array}{l}m \\
K_{\mathrm{g}} \\
\text { as } \times\end{array}$ & $\begin{array}{l}\mathrm{He} \\
\text { pta } \\
\text { ne }\end{array}$ & & $\begin{array}{l}\mathrm{He} \\
\text { xa } \\
\text { ne }\end{array}$ & & $\begin{array}{l}\text { Cyclo } \\
\text { hexa } \\
\text { ne }\end{array}$ & & $\begin{array}{l}\text { Tetrachl } \\
\text { orometh } \\
\text { ane }\end{array}$ & & $\begin{array}{l}\text { Dio } \\
\text { xan } \\
\text { e }\end{array}$ & & $\begin{array}{l}\text { Ben } \\
\text { zen } \\
\text { e }\end{array}$ & & $\begin{array}{l}\text { Methan } \\
\text { edithio } \\
\text { ne }\end{array}$ & \\
\hline & 12 & $m K$ & $\alpha_{\alpha}$ & $m K$ & $c_{\alpha}$ & $m K$ & $l_{\alpha}$ & $m K$ & $\alpha_{\alpha}$ & $m K$ & $c_{\alpha}$ & $m K$ & $\alpha_{\alpha}$ & $m K$ & $l_{\alpha}$ \\
\hline $\begin{array}{l}\text { Chlorofo } \\
\text { rm }\end{array}$ & $\begin{array}{l}- \\
29 \\
.4 \\
1\end{array}$ & $\begin{array}{l}- \\
25 . \\
2\end{array}$ & $\begin{array}{l}6 \\
2 \\
0\end{array}$ & - & - & -27 & $\begin{array}{l}7 \\
9 \\
0\end{array}$ & -24.1 & $\begin{array}{l}9 \\
2 \\
3\end{array}$ & $\begin{array}{l}- \\
34 . \\
39\end{array}$ & $\begin{array}{l}8 \\
3 \\
6\end{array}$ & -31 & $\begin{array}{l}1 \\
0 \\
0 \\
2\end{array}$ & - & - \\
\hline $\begin{array}{l}\text { Tetrachl } \\
\text { orometh } \\
\text { ane }\end{array}$ & $\begin{array}{l}0 . \\
93 \\
3\end{array}$ & - & - & 1.3 & $\begin{array}{l}5 \\
8 \\
0\end{array}$ & - & - & 1.5 & $\begin{array}{l}8 \\
2 \\
1\end{array}$ & - & - & 1.6 & $\begin{array}{l}9 \\
2 \\
1\end{array}$ & 1.12 & $\begin{array}{l}1 \\
5 \\
1 \\
8\end{array}$ \\
\hline $\begin{array}{l}\text { Methane } \\
\text { dithione }\end{array}$ & $\begin{array}{l}47 \\
.4\end{array}$ & 30 & $\begin{array}{l}6 \\
8 \\
0\end{array}$ & 30 & $\begin{array}{l}7 \\
0 \\
1\end{array}$ & 31.9 & $\begin{array}{l}8 \\
9 \\
0\end{array}$ & 27.8 & $\begin{array}{l}1 \\
0 \\
0 \\
5\end{array}$ & $\begin{array}{l}33 . \\
2\end{array}$ & $\begin{array}{l}1 \\
0 \\
7 \\
0\end{array}$ & $\begin{array}{l}27 . \\
1\end{array}$ & $\begin{array}{l}1 \\
1 \\
7 \\
1\end{array}$ & 24.9 & $\begin{array}{l}1 \\
9 \\
1 \\
4\end{array}$ \\
\hline $\begin{array}{l}\text { Acetonitr } \\
\text { ile }\end{array}$ & $\begin{array}{l}36 \\
3\end{array}$ & - & - & $\begin{array}{l}25 \\
9\end{array}$ & $\begin{array}{l}5 \\
0 \\
5\end{array}$ & 219 & $\begin{array}{l}9 \\
3 \\
5\end{array}$ & 217 & $\begin{array}{l}1 \\
0 \\
6 \\
0\end{array}$ & - & - & 244 & $\begin{array}{l}1 \\
3 \\
9 \\
0\end{array}$ & - & - \\
\hline $\begin{array}{l}\text { Methoxy } \\
\text { methane }\end{array}$ & $\begin{array}{l}- \\
8 . \\
7\end{array}$ & - & - & - & - & -8.1 & $\begin{array}{l}1 \\
1 \\
7 \\
0\end{array}$ & -5.5 & $\begin{array}{l}1 \\
3 \\
2 \\
4\end{array}$ & - & - & -6.6 & $\begin{array}{l}1 \\
5 \\
1 \\
4\end{array}$ & - & - \\
\hline $\begin{array}{l}\text { Propano } \\
\text { ne }\end{array}$ & 99 & 66 & $\begin{array}{l}6 \\
2 \\
5\end{array}$ & - & - & - & - & 93 & $\begin{array}{l}9 \\
2 \\
3\end{array}$ & - & - & 51 & $\begin{array}{l}1 \\
0 \\
3 \\
8\end{array}$ & - & - \\
\hline $\begin{array}{l}\text { Ethoxyet } \\
\text { hane }\end{array}$ & $\begin{array}{l}- \\
11 \\
.4\end{array}$ & $\begin{array}{l}- \\
8.9 \\
4\end{array}$ & $\begin{array}{l}5 \\
5 \\
9\end{array}$ & - & - & - & - & -7.5 & $\begin{array}{l}7 \\
9 \\
2\end{array}$ & - & - & -8.5 & $\begin{array}{l}1 \\
1 \\
3\end{array}$ & - & - \\
\hline
\end{tabular}




\begin{tabular}{|c|c|c|c|c|c|c|c|c|c|c|c|c|c|c|c|}
\hline & & & & & & & & & & & & & 2 & & \\
\hline Pyridine & - & 120 & $\begin{array}{l}6 \\
0 \\
5\end{array}$ & - & - & 119.2 & $\begin{array}{l}7 \\
8 \\
4\end{array}$ & 128 & $\begin{array}{l}8 \\
9 \\
2\end{array}$ & $\begin{array}{l}11 \\
1.5\end{array}$ & $\begin{array}{l}9 \\
0 \\
8\end{array}$ & - & - & - & - \\
\hline $\begin{array}{l}\text { Nitroben } \\
\text { zene }\end{array}$ & $\begin{array}{l}11 \\
32\end{array}$ & 888 & $\begin{array}{l}5 \\
4 \\
9\end{array}$ & - & - & 920 & $\begin{array}{l}6 \\
4 \\
4\end{array}$ & 880 & $\begin{array}{l}8 \\
0 \\
8\end{array}$ & $\begin{array}{l}88 \\
0\end{array}$ & $\begin{array}{l}8 \\
1 \\
4\end{array}$ & 980 & $\begin{array}{l}8 \\
9 \\
7\end{array}$ & - & - \\
\hline Benzene & $\begin{array}{l}12 \\
.8\end{array}$ & 8.3 & $\begin{array}{l}5 \\
8 \\
0\end{array}$ & $\begin{array}{l}8.5 \\
8\end{array}$ & $\begin{array}{l}5 \\
9 \\
8\end{array}$ & 8.14 & $\begin{array}{l}7 \\
5 \\
4\end{array}$ & 7 & $\begin{array}{l}8 \\
5 \\
0\end{array}$ & $\begin{array}{l}6.5 \\
7\end{array}$ & $\begin{array}{l}8 \\
6 \\
9\end{array}$ & 8.1 & $\begin{array}{l}9 \\
5 \\
5\end{array}$ & 6.3 & $\begin{array}{l}1 \\
5 \\
8\end{array}$ \\
\hline $\begin{array}{l}\text { Methylb } \\
\text { enzene }\end{array}$ & 33 & $\begin{array}{l}18 . \\
5\end{array}$ & $\begin{array}{l}5 \\
4 \\
1\end{array}$ & - & - & - & - & 13.7 & $\begin{array}{l}7 \\
8 \\
0\end{array}$ & 13 & $\begin{array}{l}8 \\
0 \\
1\end{array}$ & $\begin{array}{l}13 . \\
8\end{array}$ & $\begin{array}{l}9 \\
5 \\
0\end{array}$ & - & - \\
\hline $\begin{array}{l}\text { Phenyla } \\
\text { mine }\end{array}$ & - & - & - & - & - & 22.2 & $\begin{array}{l}7 \\
4 \\
5\end{array}$ & 12.5 & $\begin{array}{l}8 \\
4 \\
1\end{array}$ & $\begin{array}{l}51 . \\
2\end{array}$ & $\begin{array}{l}8 \\
6 \\
9\end{array}$ & $\begin{array}{l}17 . \\
2\end{array}$ & $\begin{array}{l}9 \\
4 \\
0\end{array}$ & - & - \\
\hline $\begin{array}{l}\text { 1,4- } \\
\text { Dimethyl } \\
\text { benzene }\end{array}$ & $\begin{array}{l}21 \\
.3\end{array}$ & $\begin{array}{l}15 . \\
6\end{array}$ & $\begin{array}{l}5 \\
0 \\
8\end{array}$ & - & - & 13.7 & $\begin{array}{l}6 \\
5 \\
5\end{array}$ & 10.6 & $\begin{array}{l}7 \\
3 \\
0\end{array}$ & - & - & $\begin{array}{l}14 . \\
93\end{array}$ & $\begin{array}{l}8 \\
2 \\
7\end{array}$ & - & - \\
\hline $\begin{array}{l}\mathrm{N}, \mathrm{N}- \\
\text { Dimethyl } \\
\text { aniline }\end{array}$ & - & - & - & - & - & 177 & $\begin{array}{l}6 \\
4 \\
2\end{array}$ & 158 & $\begin{array}{l}7 \\
2 \\
2\end{array}$ & $\begin{array}{l}19 \\
5\end{array}$ & $\begin{array}{l}7 \\
7 \\
4\end{array}$ & $\begin{array}{l}134 \\
.2\end{array}$ & $\begin{array}{l}8 \\
0 \\
7\end{array}$ & - & - \\
\hline $\begin{array}{l}1,2- \\
\text { Dinitrobe } \\
\text { nzene }\end{array}$ & - & - & - & $\begin{array}{l}15 \\
10\end{array}$ & $\begin{array}{l}5 \\
4 \\
9\end{array}$ & - & - & 1300 & $\begin{array}{l}7 \\
4 \\
5\end{array}$ & $\begin{array}{l}11 \\
60\end{array}$ & $\begin{array}{l}7 \\
9 \\
0\end{array}$ & $\begin{array}{l}187 \\
0\end{array}$ & $\begin{array}{l}8 \\
7 \\
5\end{array}$ & - & - \\
\hline $\begin{array}{l}1,3- \\
\text { Dinitrobe } \\
\text { nzene }\end{array}$ & - & - & - & $\begin{array}{l}55 \\
0\end{array}$ & $\begin{array}{l}5 \\
5 \\
3\end{array}$ & - & - & 580 & $\begin{array}{l}6 \\
7 \\
7\end{array}$ & $\begin{array}{l}46 \\
0\end{array}$ & $\begin{array}{l}7 \\
9 \\
5\end{array}$ & 685 & $\begin{array}{l}8 \\
8 \\
5\end{array}$ & - & - \\
\hline Octane & $\begin{array}{l}8 . \\
4\end{array}$ & - & - & $\begin{array}{l}3.3 \\
4\end{array}$ & $\begin{array}{l}4 \\
0 \\
7\end{array}$ & 2.16 & $\begin{array}{l}5 \\
6 \\
6\end{array}$ & 3.06 & $\begin{array}{l}6 \\
3 \\
4\end{array}$ & - & - & - & - & - & - \\
\hline $\begin{array}{l}\text { Bicyclo[4 } \\
.4 .0] \mathrm{deca} \\
- \\
\text { 1,3,5,7,9- } \\
\text { pentene }\end{array}$ & - & 40 & $\begin{array}{l}5 \\
3 \\
1\end{array}$ & $\begin{array}{l}49 . \\
4\end{array}$ & $\begin{array}{l}6 \\
0 \\
2\end{array}$ & 42.3 & $\begin{array}{l}6 \\
7 \\
8\end{array}$ & 40.9 & $\begin{array}{l}7 \\
6 \\
2\end{array}$ & - & - & $\begin{array}{l}45 . \\
5\end{array}$ & $\begin{array}{l}8 \\
2 \\
4\end{array}$ & 45 & $\begin{array}{l}1 \\
4 \\
1 \\
3\end{array}$ \\
\hline
\end{tabular}




\begin{tabular}{|l|l|l|l|l|l|l|l|l|l|l|l|l|l|l|l|}
\hline $\begin{array}{l}\text { Phenant } \\
\text { hrene }\end{array}$ & - & 114 & 4 & - & - & 114.1 & 5 & 97.6 & 6 & - & - & 78. & 7 & - & - \\
& & 6 & & & & 9 & & 6 & & & 8 & 3 & & \\
5 & & & & 6 & & 0 & & & & 5 & & \\
\hline
\end{tabular}

Table 2. The molar Kerr constants of non-polar compounds ( $\mathrm{mK})$ and the values of parameter gin polar solvent (chlorobenzene)

\begin{tabular}{lcccc}
\hline Compound & $m K_{\text {gas }} \times 10^{12}$ & $m K \times 10^{12}$ & $\begin{array}{c}\Delta n K=m K_{\text {gas }} \\
-m K\end{array}$ & $\varphi^{11} 0^{18}$ \\
\hline Tetrachloromethane & 2.0 & 44.3 & -42.3 & 726 \\
\hline Benzene & 15.6 & 53.3 & -27.7 & 755 \\
\hline Methanedithione & 52.3 & 49.3 & 3.2 & 814 \\
\hline
\end{tabular}

Table 3. The values of molar Kerr constant $\left(m K \rtimes 0^{12}\right)$ calculated according to Eq. (15) and the values of gas molar Kerr constants $\left(m K_{\text {gas }} \backslash 0^{12}\right)$.

\begin{tabular}{|c|c|c|c|c|c|c|c|c|c|}
\hline No & Compound & $\begin{array}{l}\text { Heptan } \\
\text { e }\end{array}$ & $\begin{array}{l}\text { Hexan } \\
\text { e }\end{array}$ & $\begin{array}{l}\text { Cyclo- } \\
\text { hexan } \\
\text { e }\end{array}$ & $\begin{array}{l}\text { Tetrachlor } \\
\text { o- } \\
\text { methane }\end{array}$ & $\begin{array}{l}\text { Dioxan } \\
\text { e }\end{array}$ & $\begin{array}{l}\text { Benzen } \\
\text { e }\end{array}$ & $\begin{array}{l}\text { Methan } \\
\text { e- } \\
\text { dithione }\end{array}$ & $\begin{array}{l}m K_{\mathrm{ga}} \\
{ }_{\mathrm{s}} \times \\
10^{12}\end{array}$ \\
\hline 1 & Chloroform & -25.2 & - & -27 & -24.12 & -34.29 & -31 & - & $\begin{array}{l}- \\
29.4 \\
1\end{array}$ \\
\hline 2 & $\begin{array}{l}\text { Tetrachlorometh } \\
\text { ane }\end{array}$ & - & 1.3 & - & 1.15 & - & 1.6 & 1.12 & $\begin{array}{l}0.93 \\
3\end{array}$ \\
\hline 3 & Methanedithione & 30 & 30 & 31.9 & 27.8 & 38.2 & 27.1 & 24.8 & 47.4 \\
\hline 4 & Acetonitrile & - & 259 & 219 & 217 & - & 244 & - & 363 \\
\hline 5 & $\begin{array}{l}\text { Methoxymethan } \\
\text { e }\end{array}$ & - & - & -8.1 & -5.5 & - & -6.6 & - & -8.7 \\
\hline 6 & Propanone & 66 & 65 & - & 93 & - & 51 & - & 99 \\
\hline
\end{tabular}




\begin{tabular}{|c|c|c|c|c|c|c|c|c|c|}
\hline 7 & Ethoxyethane & -8.94 & - & - & -7.5 & - & -8.5 & - & \begin{tabular}{|l|}
- \\
11.4
\end{tabular} \\
\hline 8 & Pyridine & 120 & - & 119.2 & 128 & 111.5 & - & - & - \\
\hline 9 & Nitrobenzene & 888 & - & 920 & 880 & 880 & 980 & - & $\begin{array}{l}133 \\
2\end{array}$ \\
\hline 10 & Benzene & 8.3 & 8.58 & 8.14 & 7 & 6.57 & 8.1 & 6.3 & 12.8 \\
\hline 11 & Phenylamine & - & - & 22.2 & 12.5 & 51.2 & 17.2 & - & - \\
\hline 12 & Methylbenzene & 18.5 & - & - & 13.7 & 13 & 13.8 & - & 33 \\
\hline 13 & $\begin{array}{l}\text { 1,4- } \\
\text { Dimethylbenzene }\end{array}$ & 15.6 & - & 13.7 & 10.6 & - & 14.93 & - & 21.3 \\
\hline 14 & $\begin{array}{l}\mathrm{N}, \mathrm{N}- \\
\text { Dimethylaniline }\end{array}$ & - & - & 177 & 158 & 195 & 134.2 & - & - \\
\hline 15 & Octane & - & 3.34 & 2.16 & 3.06 & - & - & - & 8.4 \\
\hline 16 & $\begin{array}{l}\text { Bicyclo[4.4.0]dec } \\
\text { a-1,3,5,7,9- } \\
\text { pentene }\end{array}$ & 40 & 49.4 & 42.3 & 40.9 & - & 45.5 & 45 & - \\
\hline 17 & $\begin{array}{l}\text { Triphenylmethan } \\
\text { e }\end{array}$ & - & - & 18.2 & 13.7 & - & 12.5 & - & - \\
\hline 18 & Phenanthrene & 114 & - & 114.1 & 97.6 & - & 78.5 & - & - \\
\hline 19 & Pirene & - & - & 173 & 161 & - & 160 & - & - \\
\hline
\end{tabular}

Table 4. The values of molar Kerr constant $\left(m K^{\prime} \times 10^{12}\right)$ calculated according to Eq. (16) for compounds 1-19 (see Table 3) and the molar Kerr constants $\left(m K_{\varphi_{\alpha}=0}^{\prime} \times 10^{12}\right)$ calculated by extrapolation.

\begin{tabular}{|c|c|c|c|c|c|c|c|c|}
\hline $\begin{array}{l}\text { Com- } \\
\text { pound }\end{array}$ & $m K_{\varphi_{\alpha}=0}^{\prime}$ & Heptane & Hexane & $\begin{array}{l}\text { Cyclo- } \\
\text { hexane }\end{array}$ & $\begin{array}{l}\text { Tetrachl } \\
\text { oro- } \\
\text { methan } \\
\text { e }\end{array}$ & $\begin{array}{c}\text { Dioxan } \\
\mathrm{e}\end{array}$ & $\begin{array}{c}\text { Benzen } \\
\mathrm{e}\end{array}$ & $\begin{array}{l}\text { Methan } \\
\text { e- } \\
\text { dithione }\end{array}$ \\
\hline 1 & -30 & -33 & - & -36.1 & -34 & -48 & -44.1 & - \\
\hline 2 & 1.9 & - & 1.67 & - & 1.62 & - & 2.27 & 1.59 \\
\hline 3 & 47 & 38.8 & 38.8 & 42.7 & 39.2 & 53.5 & 38.6 & 35.3 \\
\hline 4 & 362 & - & 335 & 293 & 306 & - & 348 & - \\
\hline 5 & -9 & - & - & -10.8 & -7.8 & - & -9.4 & - \\
\hline 6 & 100 & 86.4 & 84 & - & 131 & - & 72.6 & - \\
\hline 7 & -11 & -11.7 & - & - & -10.6 & - & -12.1 & - \\
\hline
\end{tabular}




\begin{tabular}{ccccccccc}
$\mathbf{8}$ & 170 & 157 & - & 160 & 180 & 156 & - & - \\
$\mathbf{9}$ & 1330 & 1168 & - & 1231 & 1240 & 1233 & 1390 & - \\
$\mathbf{1 0}$ & 13 & 10.9 & 11.1 & 10.9 & 9.9 & 9.3 & 11.5 & 9 \\
$\mathbf{1 1}$ & 45 & - & - & 29.7 & 17.6 & 72 & 24.5 & - \\
$\mathbf{1 2}$ & 31 & 24.2 & - & - & 19.3 & 18.2 & 19.7 & - \\
$\mathbf{1 3}$ & 22 & 20.4 & - & 18.3 & 14.9 & - & - & - \\
$\mathbf{1 4}$ & 350 & - & - & 237 & 223 & 213 & 191 & - \\
$\mathbf{1 5}$ & 8.5 & - & 4.4 & 2.9 & 4.3 & - & - & - \\
$\mathbf{1 6}$ & 65 & 52.4 & 63.8 & 56.6 & 57.8 & - & 64.8 & 64 \\
$\mathbf{1 7}$ & 50 & - & - & 24.4 & 19.3 & - & 17.8 & - \\
$\mathbf{1 8}$ & 230 & 149 & - & 153 & 138 & - & 112 & - \\
$\mathbf{1 9}$ & 234 & - & - & 232 & 227 & - & 228 & - \\
\hline
\end{tabular}

Table 5. The values of molar Kerr constant $\left(m K^{\prime \prime} \times 10^{12}\right)$ calculated according to Eq. (17) for compounds 1-19 (see Table 3) and the molar Kerr constants $\left(m K_{\varphi_{\alpha}=0}^{\prime \prime} \times 10^{12}\right)$ calculated by extrapolation

\begin{tabular}{|c|c|c|c|c|c|c|c|c|}
\hline $\begin{array}{l}\text { Com- } \\
\text { pound }\end{array}$ & & Heptane & Hexane & $\begin{array}{l}\text { Cyclo- } \\
\text { hexane }\end{array}$ & $\begin{array}{l}\text { Tetrachloro- } \\
\text { methane }\end{array}$ & Dioxane & Benzene & $\begin{array}{l}\text { Methane- } \\
\text { dithione }\end{array}$ \\
\hline 1 & -14 & -43.2 & - & -50.4 & -46.8 & -64.4 & -62.6 & - \\
\hline 2 & 2.2 & - & 2.17 & - & 2.23 & - & 3.23 & 2.47 \\
\hline 3 & 54 & 51.4 & 50.3 & 59.5 & 53.9 & 71.8 & 54.7 & 54.6 \\
\hline 4 & * & - & 434 & 408 & 421 & - & 492 & - \\
\hline 5 & - & - & - & -15.1 & -10.7 & - & -13.3 & - \\
\hline 6 & 125 & 113 & 109 & - & 180 & - & 103 & - \\
\hline 7 & - & -15.3 & - & - & -14.6 & - & -17.2 & - \\
\hline 8 & - & 206 & - & 222 & 248 & 209 & - & - \\
\hline 9 & - & 1521 & - & 1717 & 1708 & 1653 & 1979 & - \\
\hline 10 & 15.8 & 14.2 & 14.4 & 15.2 & 15.3 & 12.3 & 16.4 & 13.9 \\
\hline 11 & - & - & - & 41.4 & 24.3 & 96.2 & 34.7 & - \\
\hline 12 & 33 & 31.7 & - & - & 26.6 & 24.2 & 27.9 & - \\
\hline 13 & - & 36.7 & - & 25.6 & 20.6 & - & - & - \\
\hline 14 & - & - & - & 330 & 307 & 286 & 270 & - \\
\hline 15 & - & - & 5.6 & 4.03 & 5.94 & - & - & - \\
\hline 16 & - & 68.5 & 82.8 & 78.9 & 79.4 & - & 91.9 & 99.2 \\
\hline 17 & - & - & - & 34 & 26.6 & - & 25.2 & - \\
\hline 18 & - & 195 & - & 213 & 189 & - & 158 & - \\
\hline 19 & - & - & - & 323 & 312 & - & 323 & - \\
\hline
\end{tabular}

*Missing $m K_{\varphi_{\alpha}=0}^{\prime \prime}$ values mean that the spread and the small number of experimental points do not provide $m K_{\varphi_{\alpha}=0}^{\prime \prime}$ values according to the extrapolation formula (17) 
Fig. 1

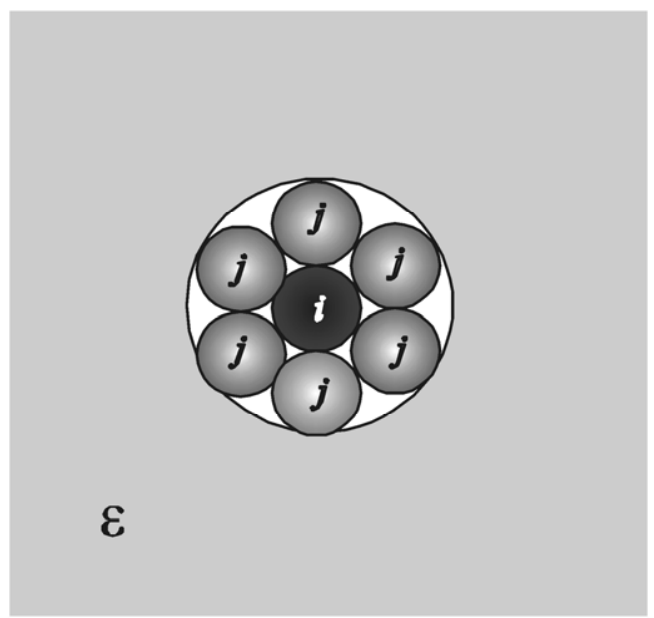

Fig. 2

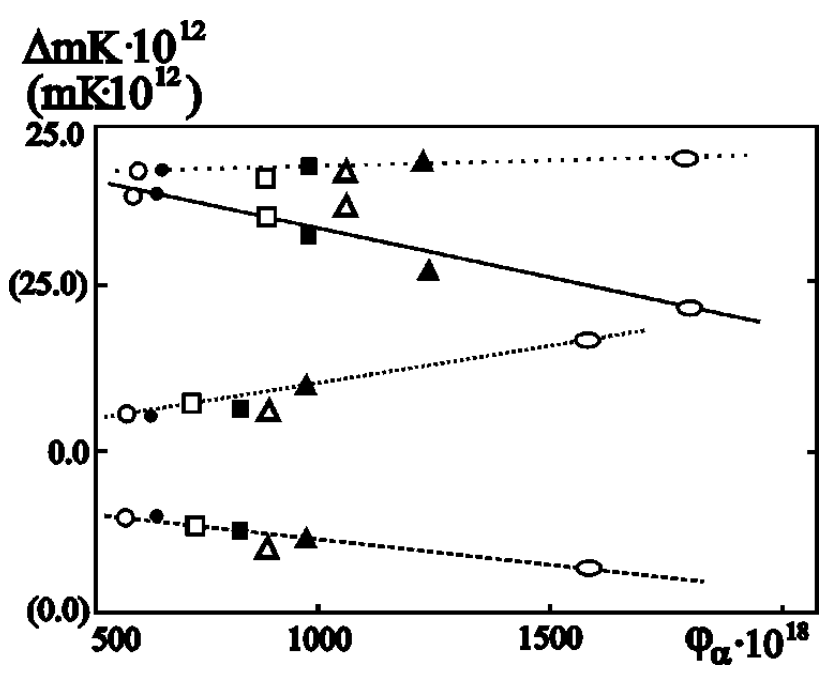


Fig. 3

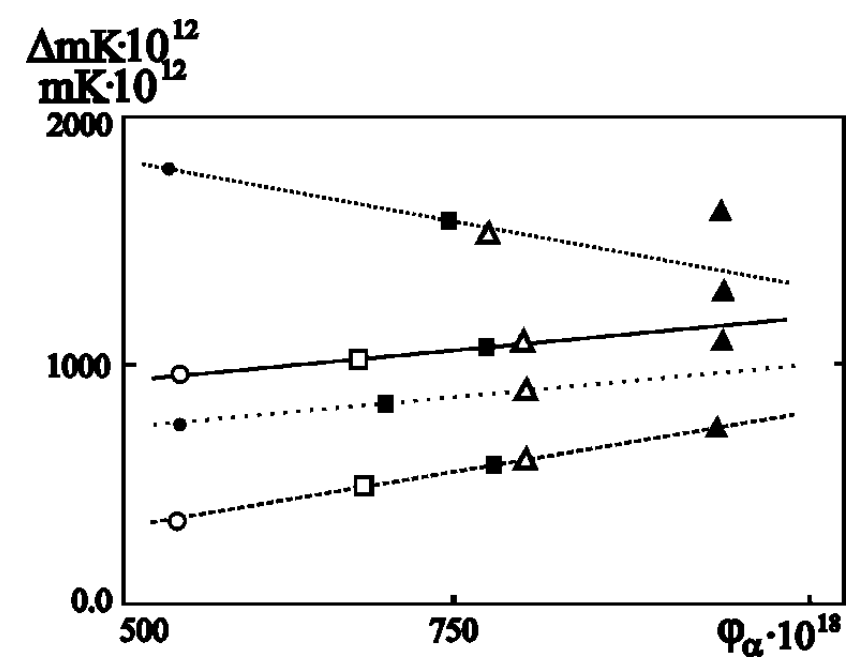

Fig. 4

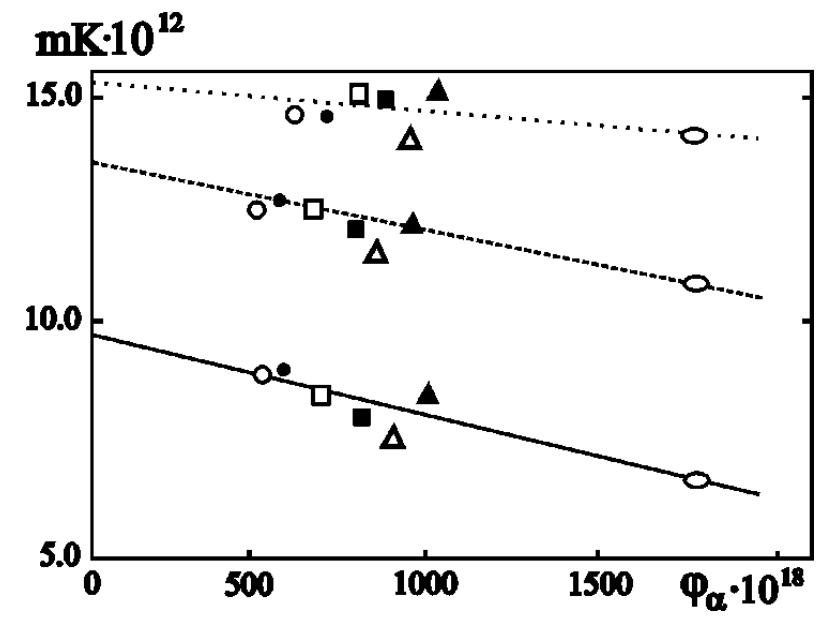


Fig. 5

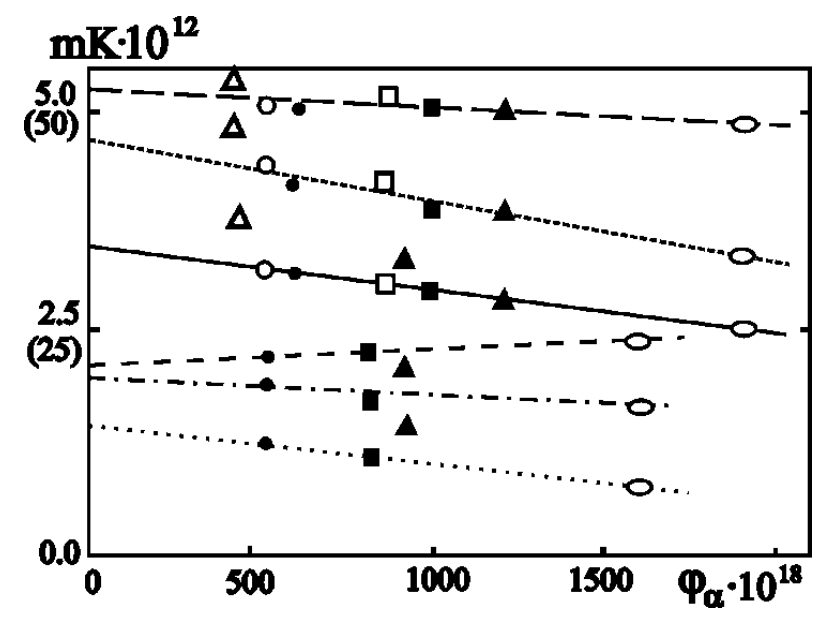

Fig. 6

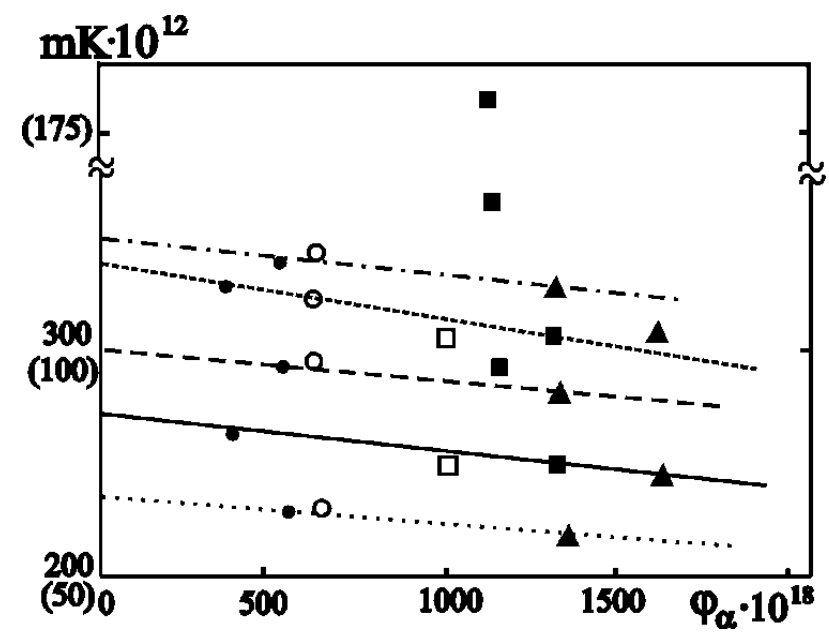


Graphical abstract

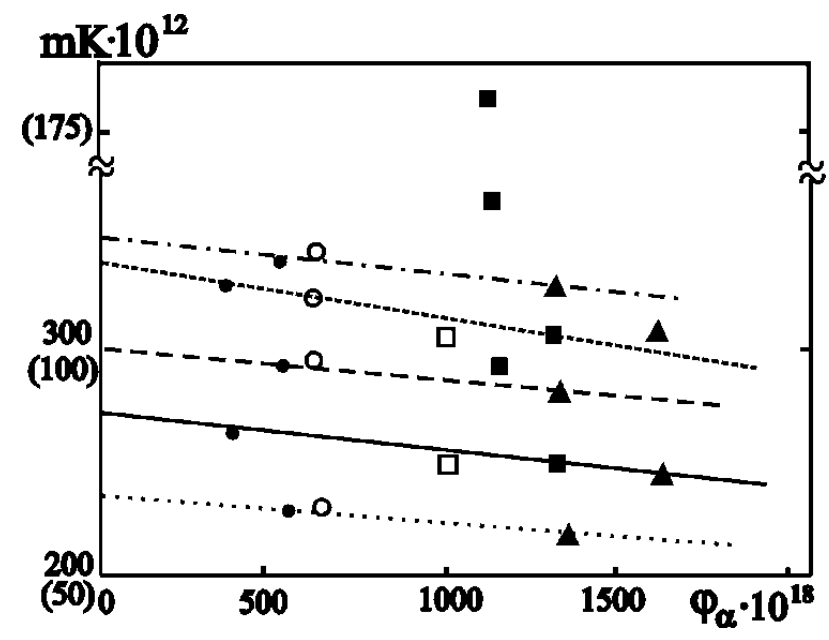

